\title{
Smart Aquarium Design Using Raspberry Pi and Android Based
}

\author{
Khairunisa $^{1}$, Mardeni $^{2}$, Yuda $\operatorname{Irawan}^{3 *}$ \\ 1,2 Department of Computer Science, STMIK Hang Tuah Pekanbaru, Pekanbaru, Indonesia \\ ${ }^{3}$ Department of Information System, STMIK Hang Tuah Pekanbaru, Pekanbaru, Indonesia \\ Email: ${ }^{1}$ khairunisa6494@gmail.com, ${ }^{2}$ mdn@ @tp.ac.id, ${ }^{3}$ yudairawan89@gmail.com \\ *Corresponding Author
}

\begin{abstract}
From this problem, a smart aquarium device was designed to feed aquaculture fish automatically, namely Smart Aquarium Design Using Android-Based Raspberry Pi, designed to provide convenience in the process of maintaining fish in an aquarium. This aquarium can perform several actions such as fish feeding automatically can be done using Android via the internet network and control the aquarium decorative lights. To move the fish feeding valve, it uses a servo motor to drive the fish feeding valve and also uses a relay as an on / off aquarium decorative light. Fish feed machines can feed fish on a scheduled basis if the user forgets to feed fish. Smart aquarium is also equipped with a water filter so that aquarium water does not need to change water.
\end{abstract} Relay

Keywords-Aquarium, Android, Motor Servo, Rasberry pi,

\section{INTRODUCTION}

For aquarium owners, sometimes their daily activities are busy with other busy activities was studied by nusantara [1]. With this density of activity, it often makes it difficult for fish aquarium owners to provide fish with the feeding process, which is usually done manually when at home was studied by pasha [2].

Nowadays, technology is developing rapidly in everyday life. Where the development of these technologies provides advantages and disadvantages of each. One of the advantages is the technology can remotely control the aquarium to feed the fish with android was studied by irawan [3].

Research with the theme Smart Aquarium has been done before, such as vishwas [4] with the title Smart Aquarium Application based on Mobile and Short Message Service, which is to automatically feed fish by entering the program on Arduino by sending an SMS to a predetermined phone number was studied by fatmawati [5].

With the technology available today, showing additions and changes to features in previous studies including automatic feeding of fish with android is done by setting a predetermined schedule was studied by daut [6]. With the feeding that has been designed automatically, the user does not need to worry about forgetting and having to be there when feeding his pet fish was studied by muhardi [7]. In addition, this tool can also control the lights in the aquarium was studied by Tolentino [8].

Based on the above background, the authors provide a solution by designing a tool for the thesis entitled "Smart Aquarium Design Using Android-based Raspberry Pi" was studied by sohor [9]. To adjust the tool that will be made with developing technology, the tool will be made using the Android-based Raspberry Pi was studied by harani [10]. Where, Android will be the interface between the aquarium and the tools to be made was studied by irawan [11]. Android is a Linux-based information system used for smartphones was studied by ulum [12]. By using Android on a smartphone, the aquarium owner can feed fish anytime and anywhere was studied by shin [13].

Raspberry $\mathrm{Pi}$, or commonly abbreviated as Raspi, is a single-board circuit microcomputer module was studied by jorda [14]. Has the size of a credit card and has a digital input output port like on a microcontroller board was studied by wahyuni [15]. Raspi can be used to run office programs, computer game programs, and as a media player to high-resolution videos was studied by afifah [16]. The advantages of the Raspberry $\mathrm{Pi}$ compared to the microcontroller board are that it has a port / connection for a display in the form of a TV or PC monitor and a USB connection for the keyboard and mouse was studied by irawan [17]. The goal of creating the Raspberry Pi was to make an inexpensive device that would improve programming skills and hardware understanding at the preuniversity level was studied by Budiman [18]. Due to its small size and affordable price, it can quickly be adopted by electronics enthusiasts, makers and hobbyists for projects that require more than a basic microcontroller (Raspberry device) was studied by irawan [19].

\section{METHODS}

In this study, the authors used the Prototype Model research method. In the Prototype model, the process of creating a system that is made will be structured was studied by salim [20]. How many stages must be passed in the making, namely gathering needs, designing and evaluating was studied by Abdullah [21]. If the final stage states that the system that has been created is not perfect or still has flaws, the system will be re-evaluated and will go through the process from the beginning was studied by irawan [22]. The stages in this prototype model are as follows:

\section{Data Collection}

Researchers will collect data that will be managed as consideration or study in this research in order to make decisions at a later stage was studied by kim [23].

\section{Building Prototyping}


The design is done quickly and the design represents all known aspects of the hardware device and this design forms the basis for the manufacture of a clothesline lifting device in the form of a prototype was studied by cater [24].

\section{Evaluation of Prototyping}

Furthermore, after the prototyping development stage, the researcher will define the format and requirements of the entire device, identify all requirements, and an outline of the system to be made.

\section{Encoding the System}

At this stage, the correct prototyping will be translated into programming in the form of the $\mathrm{C}$ programming language.

\section{Testing the Device}

At the testing stage of the device, the coding that has been previously made will be tested whether it can run well or if there are still parts that need to be repaired or whether there are still parts that are not as expected.

\section{Evaluation Device}

Device evaluation is not a prototyping evaluation, device evaluation is evaluating the entire finished device whether it is as desired or not. If not, then the device will be revised again and return to stages 4 and 5 . If the system has been said $\mathrm{OK}$ and has passed the test, then the device is ready to use.

\section{IMPLEMENTATION}

\section{A. Hardware Design}

The diagram block design applied in this study can be seen in Figure 1.

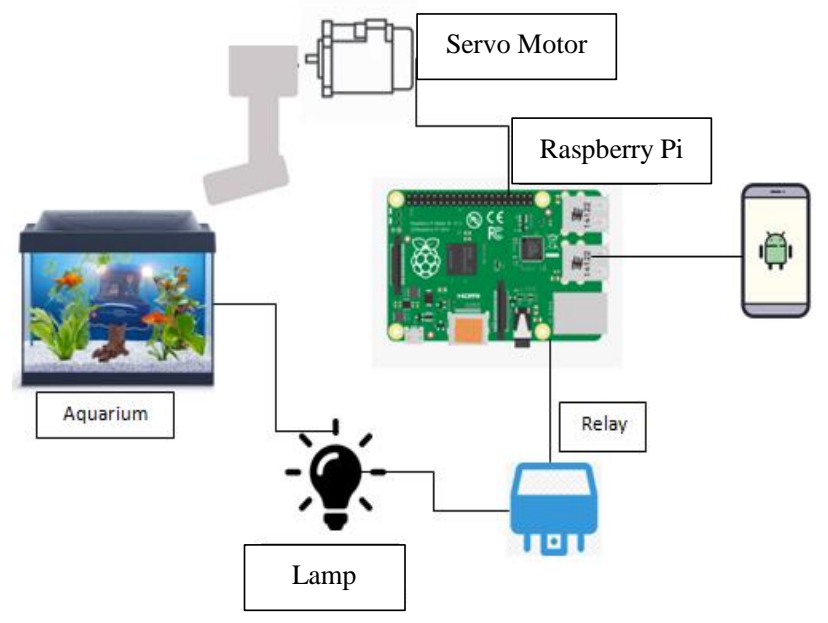

Fig. 1 Block Diagram

Figure 1 shows the system process flow used in this study. In the picture there is a servo motor, raspberry $\mathrm{Pi}$, relay, decorative lights and android. Fish feeding in the aquarium can be set on Android. When it's time, the raspberry pi will give an order to the servo motor to open the food valve, then the food will come out. This tool can control the on or off of decorative lights where the decorative lights will turn on at $6 \mathrm{pm}$ and will turn off at 6 am, the raspberry pi will be connected to a decorative light relay.

The research design is needed to make it easier for researchers to carry out and achieve goals according to a predetermined flow. The following is the design of the research tool that will be made as follows:

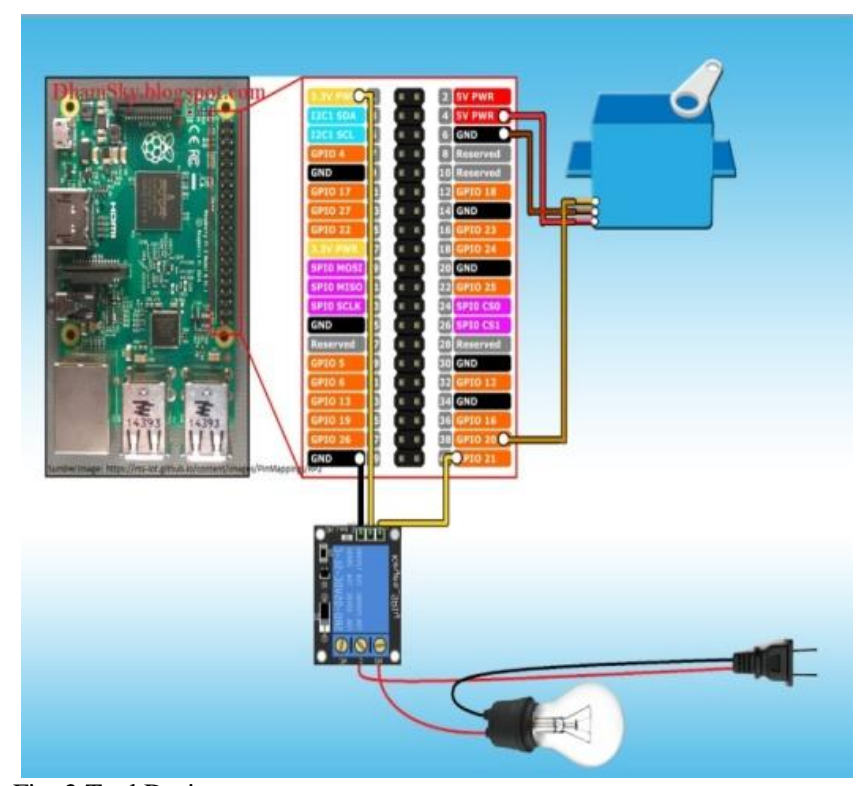

Fig. 2 Tool Design

Figure 2 shows a series of motor safety systems consisting of several devices (hardware), each component has its respective duties including:

1. Raspberry pi as a microcontroller which controls the connected devices.

2. The servo motor functions as a valve driving the fish food cover.

3. The relay functions as a connecting switch and an electric circuit breaker in decorative lamps

The Arduino Uno pins that will work on this system are:

1. GND pin as negative current for all devices.

2. 3.3V VCC pin for decorative lamp electric current.

3. The $5 \mathrm{~V}$ VCC pin for the electric current at StepDown, which will later be lowered to $4 \mathrm{~V}$ for the electric stress on the servo motor.

4. Pin PIO $21 \&$ PIO 20 as a data receiver.

\section{RESULTS OF TOOL IMPLEMENTATION}

The results of the study with the title "Smart aquarium design using android based raspberry pi" were implemented in accordance with the design in CHAPTER IV. The results can be seen in the Figure 3 and Figure 4.

This smart aquarium using an Android-based raspberry pi uses several hardware components to be able to perform a work system. The hardware components are raspberry pi, relay, decorative lights, servo motor, oxygen pump, water filter, while the software component that supports the smart aquarium working system is an android application.

In this tool there is a decorative lamp that is connected to a light relay mounted on the aquarium wall. For the location of fish food, it is made in the form of a tube at the end of 
which there is a servo motor that can open the valve to drop fish food when the application user enters the fish feeding schedule according to the desired schedule. Prototype results can be seen in Figure 5 .

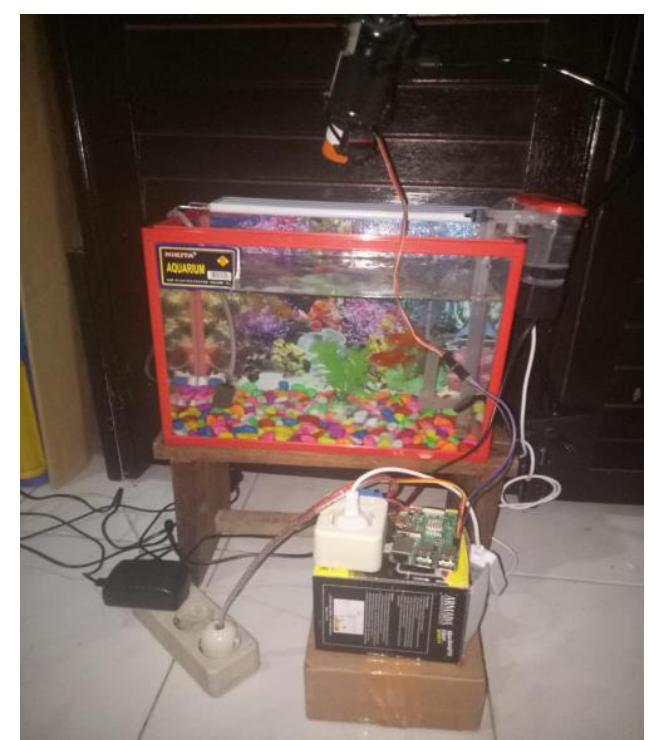

Fig. 3. Hardware Devices

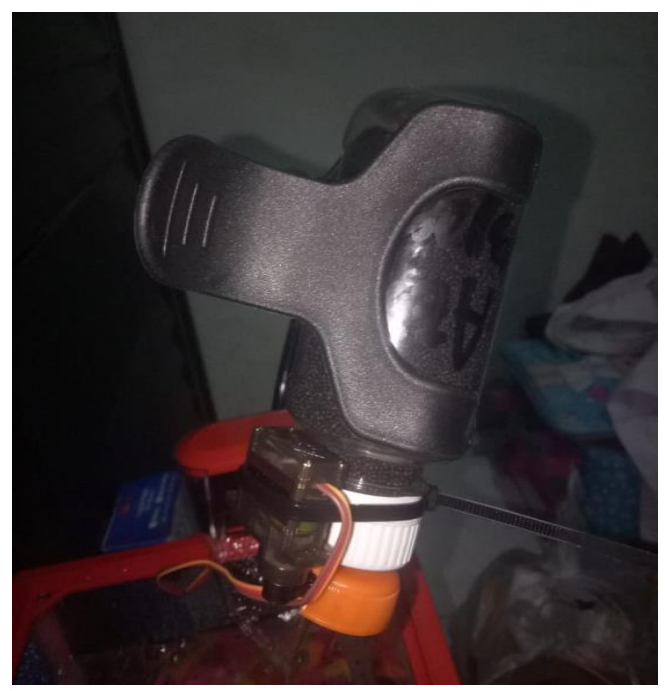

Fig. 4. Fish Appearance

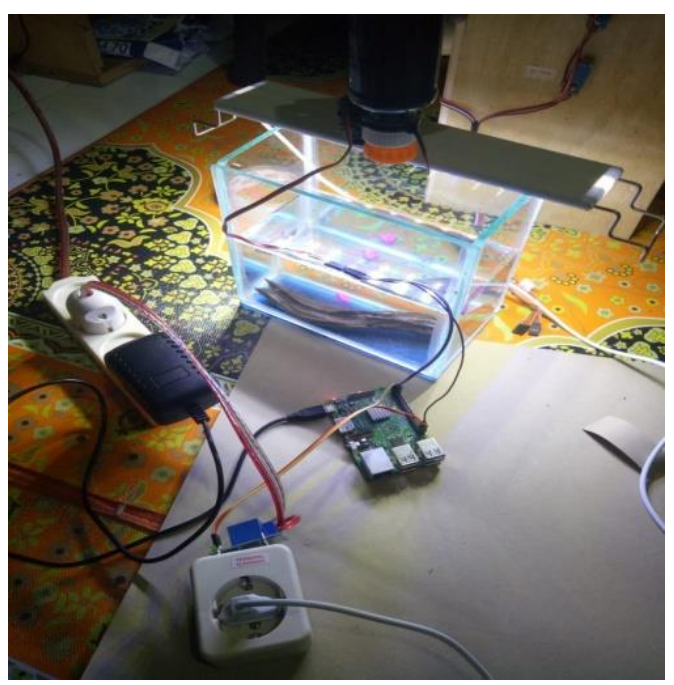

Fig. 5. Aquarium Decorative Lights

\section{A. Android Interface}

In Figure 6, you can see the initial display of this application, which is an Aquarium image that functions as information with a 3 second splash display. After 3 seconds, this display will direct the user to the next screen.

In Figure 7 is the main display result on the application for Smart Aquarium. This display displays the application logo, a decorative light notification image, an add schedule button and fish feeding schedule data on the smart akurium. In the schedule data, feeding hours, the level of food to be given and the user can delete the schedule that has been set.

In Figure 8 is the result of the added schedule display on the application for smart aquarium feeding. This view shows the application logo. The user can select the level of food to be given and the feeding hour which ends with the save button.

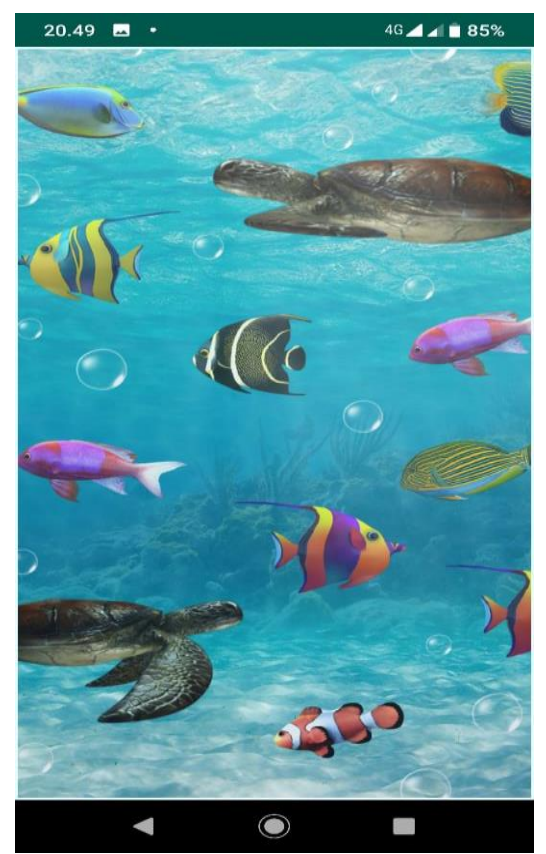

Fig. 6. Splash View
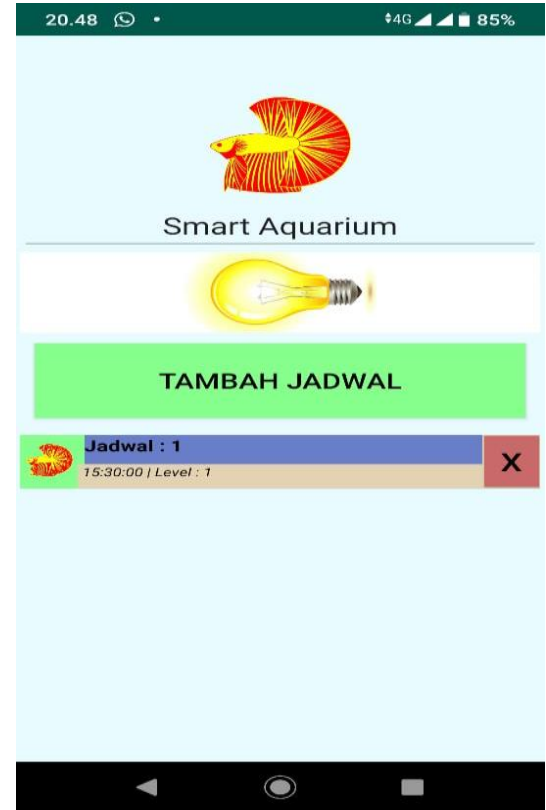

Fig. 7. Home Display 


$$
20.48
$$

\section{$4 \mathrm{G}-4 \mathrm{~B} 8 \mathrm{5} \%$}

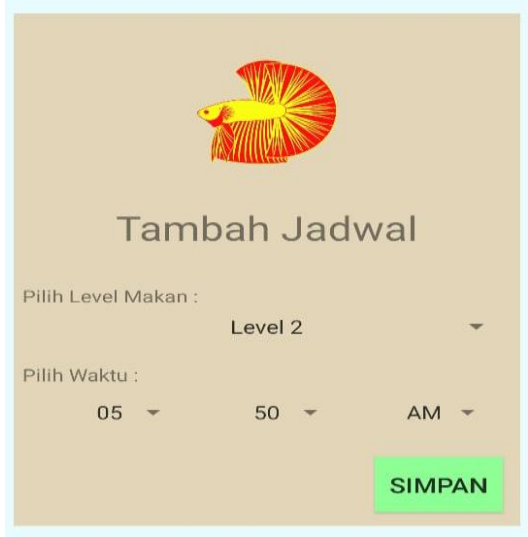

Fig. 8. View Add Schedule

\section{4}

( )

\section{$\square$}

\section{B. Testing}

The trial was carried out to find out whether this final project was going as desired. Some of the parameters that must be considered are as follows:

Testing the Performance of the Raspberry Pi

a. By making a simple program and checking the output whether it matches the program that has been made.

b. Make a program whether the smart aquarium can feed with instructions from android.

c. Testing the program to select the level of food that is issued by changing the time on the Android display.

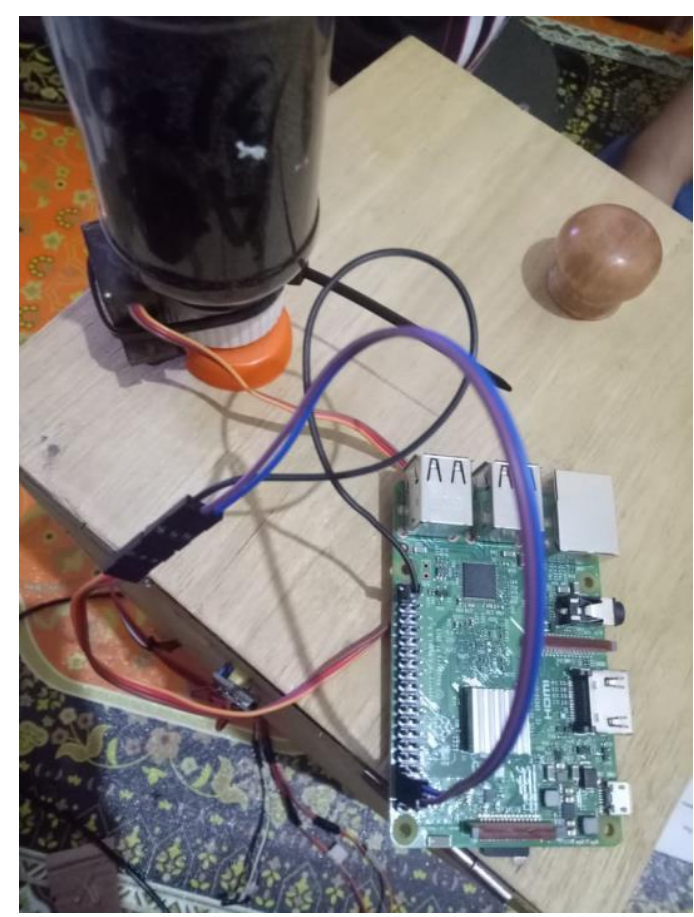

Fig. 9. Raspberry Pi circuit

\section{Fish Feeder Testing}

This test is done by the user inputting the fish feeding schedule in the android application, which is in accordance with the schedule that has been set in the android application. If the request is fulfilled, the servo will turn the valve on the feeder according to the schedule that has been entered by the user, if the request is not fulfilled, the servo will close the feeding valve.

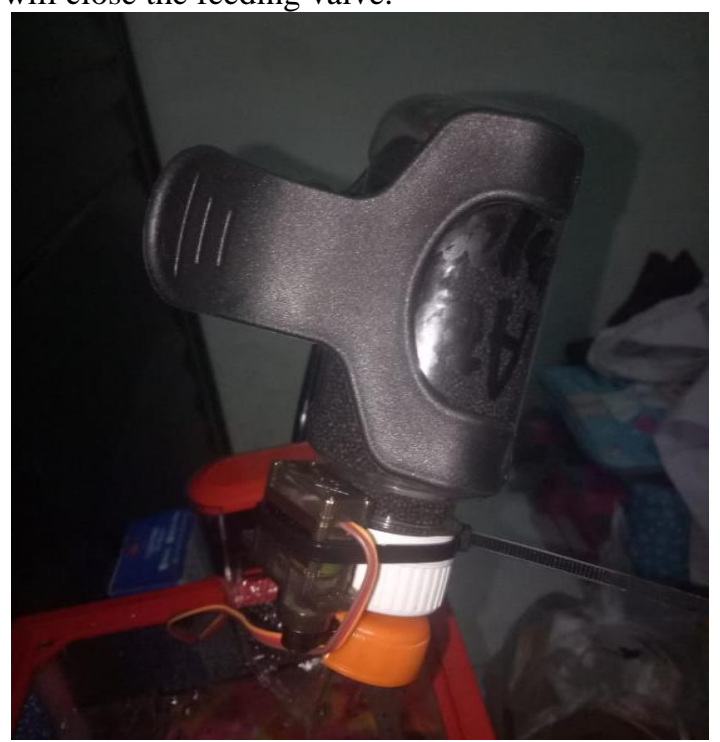

Fig. 10. Fish Appearance

Table I is a table for testing fish feeding using a smart aquarium application:

\begin{tabular}{|c|c|c|c|c|c|}
\multicolumn{7}{c|}{ TABLE I. FISH FEEDER TESTING } \\
\hline \multirow{2}{*}{ Time } & \multicolumn{2}{|c|}{ Eating Level } & \multirow{2}{*}{ Weight } & Information \\
\cline { 2 - 5 } & $\mathbf{1}$ & $\mathbf{2}$ & $\mathbf{3}$ & & \\
\hline 09.30 & $\sqrt{ }$ & & & 0.1 gram & Food comes out for 0.5 seconds \\
\hline \multirow{2}{*}{09.30} & & & & & Food comes out for 1 seconds \\
& & $\sqrt{ }$ & & 0.3 gram & \\
\hline 09.30 & & & $\sqrt{ }$ & 0.5 gram & Food comes out for 1.5 seconds \\
\hline
\end{tabular}

\section{Testing Aquarium Decorative Lights}

This test is conducted to find out whether the decorative lights can turn on or not, the lights will turn on at 6 in the afternoon and will turn off at 6 in the morning. The Table II is a table for testing aquarium decorative lights.

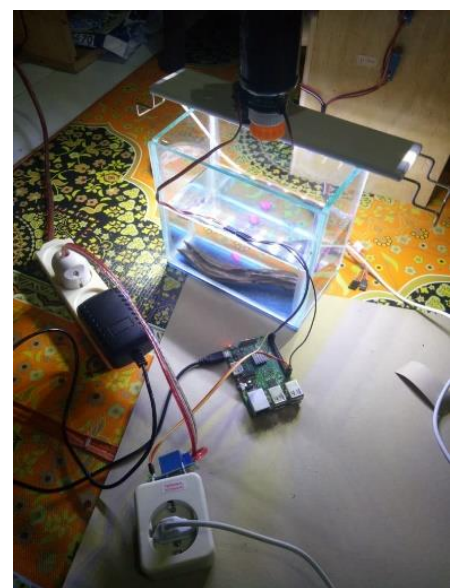

Figure 11. Aquarium Decorative Lights 
TABle 2. Testing Aquarium Decorative Lights

\begin{tabular}{|c|c|c|}
\hline \multirow{2}{*}{ Testing Time } & \multicolumn{2}{|c|}{ Lamp Status } \\
\hline & On & Off \\
\hline 06.00 & & $\sqrt{ }$ \\
\hline 21.00 & $\sqrt{ }$ & \\
\hline 13.00 & & $\sqrt{ }$ \\
\hline 18.00 & $\sqrt{ }$ & \\
\hline
\end{tabular}

\section{CONCLUSION}

After conducting experiments on Smart Aquarium Design Using android-based raspberry pi, the following conclusions were drawn: The system design is in accordance with the design made. The design is a tool that can feed the fish automatically and can run its features. The android application-based interface is in accordance with the design, namely the Android application can perform monitoring. Based on the tests that have been done, this tool can feed fish on a scheduled or manual basis. The feeding process is done automatically; the servo will rotate the fish feeding valve. The process was tested 5 times with 100\% success. The on / off process for decorative lamps is applied, in testing 4 times the success rate is $80 \%$. Android sends data to the database later and the rasberry pi will read the data in the database.

\section{REFERENCES}

[1] A. H. S. Nusantara, R. Wijaya and A. N. Jati, "Hardware design of automatic Arowana raiser," 2016 International Conference on Information Technology Systems and Innovation (ICITSI), Bandung, 2016, pp. 1-5, doi: 10.1109/ICITSI.2016.7858223.

[2] A. K. Pasha Mohd Daud, N. A. Sulaiman, Y. W. Mohamad Yusof and M. Kassim, "An IoT-Based Smart Aquarium Monitoring System," 2020 IEEE 10th Symposium on Computer Applications \& Industrial Electronics (ISCAIE), Malaysia, 2020, pp. 277-282, doi: 10.1109/ISCAIE47305.2020.9108823.

[3] Irawan, Y., Fernando, Y., \& Wahyuni, R. Detecting Heart Rate Using Pulse Sensor As Alternative Knowing Heart Condition. Journal of Applied Engineering and Technological Science (JAETS),2019, 1(1), pp 30-42.

[4] H. N. Vishwas and S. Ullas, "Remotely Monitored Energy EfficientMethod for Aquaculture Using Smart Devices," 2019 International Conference on Advances in Computing, Communication and Control (ICAC3), Mumbai, India, 2019, pp. 16, doi: 10.1109/ICAC347590.2019.9036810.

[5] Fatmawati, Kiki, et al. Rancang Bangun Tempat Sampah Pintar Menggunakan Sensor Jarak Berbasis Mikrokontroler Arduino. Riau Journal Of Computer Science, 2020, 6.2: 124-134.

[6] I. Daut, M. Irwanto and S. Hardi, "Photovoltaic powered uninterruptible power supply using smart relay," 2010 4th International Power Engineering and Optimization Conference (PEOCO), Shah Alam, 2010, pp. 453-457, doi: 10.1109/PEOCO.2010.5559175.

[7] Muhardi, Muhardi, et al. "Design Of Web Based LMS (Learning Management System) in SMAN 1 Kampar Kiri Hilir." Journal of Applied Engineering and Technological Science (JAETS) 1.2 (2020): 70-76.

[8] Tolentino, Lean Karlo S., et al. Development of an IoT-based Intensive Aquaculture Monitoring System with Automatic Water Correction. International Journal of Computing and Digital Systems, 2020, 9: 1-11.
[9] Sohor, Suherman, Et Al. Rancang Bangun Tempat Sampah Otomatis Mengunakan Mikrokontroler Dan Sensor Ultasonik Dengan Notifikasi Telegram. Jurnal Ilmu Komputer, 2020, 9.2: 154-160.

[10] N. H. Harani, A. S. Sadiah and A. Nurbasari, "Smart Fish Feeder Using Arduino Uno With Fuzzy Logic Controller," 2019 5th International Conference on Computing Engineering and Design (ICCED), Singapore, Singapore, 2019, pp. 1-6, doi: 10.1109/ICCED46541.2019.9161114.

[11] Irawan, Yuda. "Implementation Of Data Mining For Determining Majors Using K-Means Algorithm In Students Of SMA Negeri 1 Pangkalan Kerinci." Journal of Applied Engineering and Technological Science (JAETS) 1.1 (2019): 17-29.

[12] Ulum, M., et al. Smart aquaponic system based Internet of Things (IoT). In: Journal of Physics: Conference Series. IOP Publishing, 2019. p. 012047.

[13] K. J. Shin, A. V. Angani and M. Akbar, "Fully automatic fluid flow control system for smart vertical aquarium," 2017 International Conference on Applied System Innovation (ICASI), Sapporo, 2017, pp. 424-427, doi: 10.1109/ICASI.2017.7988443.

[14] Wahyuni, Refni; Irawan, Yuda. Web-Based Heart Disease Diagnosis System With Forward Chaining Method (Case Study Of Ibnu Sina Islamic Hospital). Journal Of Applied Engineering And Technological Science (Jaets), 2019, 1.1: 43-50.

[15] AFIFAH, Yasmine; ROSADI, Rizal Abdulrozaq; HAFIZ, Mohammad Raihan. The smart monitoring and automation control system for fish aquarium based on internet of things technology. In: AIP Conference Proceedings. AIP Publishing LLC, 2019. p. 030018.

[16] Ordila, Rian, et al. Penerapan Alat Kendali Kipas Angin Menggunakan Microcontroller Arduino Mega 2560 Dan Sensor Dht22 Berbasis Android. Riau Journal Of Computer Science, 2020, 6.2: $101-106$

[17] Irawan, Yuda; Wahyuni, Refni; Fonda, Hendry. Folding Clothes Tool Using Arduino Uno Microcontroller And Gear Servo. Journal of Robotics and Control (JRC), 2020, 2.3: 170-174.

[18] F. Budiman, M. Rivai and M. A. Nugroho, "Monitoring and Control System for Ammonia and $\mathrm{pH}$ Levels for Fish Cultivation Implemented on Raspberry Pi 3B," 2019 International Seminar on Intelligent Technology and Its Applications (ISITIA), Surabaya, Indonesia, 2019, pp. 68-73, doi: 10.1109/ISITIA.2019.8937217.

[19] Irawan, Yuda. Moving Load Robot Using Wifi Network and Android Based. Journal of Robotics and Control (JRC), 2020, 2.3: 217-220.

[20] T. I. Salim, T. Haiyunnisa and H. S. Alam, "Design and implementation of water quality monitoring for eel fish aquaculture," 2016 International Symposium on Electronics and Smart Devices (ISESD), Bandung, 2016, pp. 208-213, doi: 10.1109/ISESD.2016.7886720.

[21] Abdullah, Nur Dalila, et al. Smart Feeder Monitoring Devices with Mobile Application. Journal of Design for Sustainable and Environment, 2019, 1.1.

[22] Irawan, Yuda. Penerapan Data Mining Untuk Evaluasi Data Penjualan Menggunakan Metode Clustering Dan Algoritma Hirarki Divisive Di Perusahaan Media World Pekanbaru. Jurnal Teknologi Informasi Universitas Lambung Mangkurat (JTIULM), 2019, 4.1: 13-20.

[23] KIM, Yuhwan, et al. Realization of IoT based fish farm control using mobile app. In: 2018 International Symposium on Computer, Consumer and Control (IS3C). IEEE, 2018. p. 189-192.

[24] N. E. Cater, P. Eng. and T. O'Reilly, "Promoting interoperable ocean sensors the Smart Ocean Sensors Consortium," OCEANS 2009, Biloxi, MS, 2009, pp. 1-6, doi: 10.23919/OCEANS.2009.5422448. 